\title{
PREDICTION OF DYNAMIC AND QUASI-STATIC IMPACTS ON VERTICAL SEA WALLS CAUSED BY AN OVERTOPPED BORE
}

\author{
Maximilian Streicher ${ }^{l}$, Andreas Kortenhaus ${ }^{1}$, Vincent Gruwez ${ }^{1}$, Bas Hofland ${ }^{2}$, Xuexue Chen ${ }^{5}$, Steven Hughes ${ }^{3}$, \\ Matthias Hirt ${ }^{4}$
}

\begin{abstract}
This study comprises a detailed description of the individual overtopped bore impact processes against a vertical wall, situated on top of a dike. A twin peak force impact signal shape was observed with two distinct peaks during every impact. The two peaks were assigned consecutively to the dynamic components (thickness and velocity) or hydrostatic components (run-up of water at the wall) of the impacting bore. The two peaks were termed dynamic $F_{1}$ and quasistatic $F_{2}$ impact respectively. Based on available literature semi-empirical equations to describe either the dynamic $F_{1}$ or quasi-static $F_{2}$ impact force were investigated and the prediction accuracy evaluated using impact force data from large-scale experiments. The prediction accuracy of the dynamic $F_{1}$ impacts was very low. The prediction accuracy of the quasi-static impact $F_{2}$ was increased based on fitting the hydrostatic theory to the maximum run-up measurement at the wall. Based on these findings $80 \%$ of the maximum run-up height was effectively contributing to the maximum quasi-static force $F_{2}$ on the wall. The results coincided well with previous small-scale studies (Chen et al. 2012). After deconstructing the process chain preceding an impact, using the physically most meaningful parameters to predict the impact force, evaluating on a range of existing approaches, and observing the scattered prediction results, it was concluded that the impact behavior is highly stochastic and statistical analysis would be more beneficial.
\end{abstract}

Keywords: wave impact, pressure and force, quasi-static and dynamic impact, overtopping flow, large-scale experiments

\section{INTRODUCTION}

The coastlines of Belgium, The Netherlands, and parts of Germany are comprised of a sandy or muddy, mildly sloping foreshore (ranging between 1-to-10 and 1-to-250 slope angle). Often at the end of the foreshore a dike is built to prevent flooding. The water depths at the dike toe are shallow to extremely shallow. Especially in Belgium the dike crest is constructed with a certain width, a promenade, to allow for an increasing variety of leisure activities on the dike and to facilitate construction of buildings as close as possible to the sea. These buildings, and any additional hard structure protection, such as storm walls, have to withstand eventual wave impacts by overtopped water bores in case of high tides, storm events or sea level rise (IPCC 2014). For both buildings and storm walls, the bore impact force is a key parameter for a reliable and safe structural design. Theoretically, the impact at the wall is the result of a deterministic process chain starting with the I) wave breaking in shallow waters, II) wave run-up at the dike, wave overtopping over the dike crest, III) transformation of the bore flow on the promenade and IV) finally impact of the bore at the wall (Figure 1). Additionally interaction patterns of the bore, such as V) catch- up, VI) sequential overtopping or VII) anticipated collision of a reflected bore with new incoming water were observed (Streicher et al. 2018, Chen 2016). If each physical process could be described correctly, a perfect link between the waves in I) and the impact force in IV) would be the result. For each part in the process chain an output parameter would be calculated, which again serves as the input for the next. However, due to small fluctuations in the flow, turbulent processes, air entrainment, wave interaction, and other processes, this remains a challenge. Hence, the existing design formula are often of empirical nature, derived from small-scale experiments, which may not capture all the physical processes. The key objectives of this study are (1) to review the existing empirical and semi-empirical approaches for their predictive capability in mildly sloping foreshore and shallow water conditions for irregular waves; (2) to study how well they capture the underlying physical process; and (3) to adapt the approaches based on large-scale measurement data if necessary.

\section{Existing Semi-Empirical Impact Force Formulae}

It was previously observed that the impact of an overtopped water bore created a double peak impact force signal shape (Streicher et al. 2018, Chen 2016, Van Doorslaer et al. 2016, Chen et al. 2014, De

\footnotetext{
${ }^{1}$ Dept. of Civil Engineering, Ghent University, Technologiepark 904, B-9052 Zwijnaarde (Ghent), Belgium

${ }^{2}$ Faculty of Civil Engineering and Geosciences, Delft University of Technology, Stevinweg 1, 2628 CN Delft, The Netherlands

${ }^{3}$ Engineering Research Center, Department of Civil and Environmental Engineering, 1320 Campus Delivery, Colorado State University, Fort Collins, CO 80523-1320, United State

${ }^{4}$ Research Institute for Water and Environment (fwu), University of Siegen, Paul-Bonatz-Straße 9-11, 57076 Siegen, Germany

${ }^{5}$ HaskoningDHV Nederland B.V, George Hintzenweg 85, 3068AX Rotterdam
} 
Rouck et al. 2012, Ramachandran et al. 2012, Martin et al. 1999, Ramsden 1996). The first peak $F_{1}$ was related to the dynamic impact of the bore against the wall, and the second peak $F_{2}$ to the hydrostatic pressure after maximum run-up at the wall. Existing formulae to predict the maximum impact force are therefore evaluated on whether they rather describe the first peak or second peak in the impact force
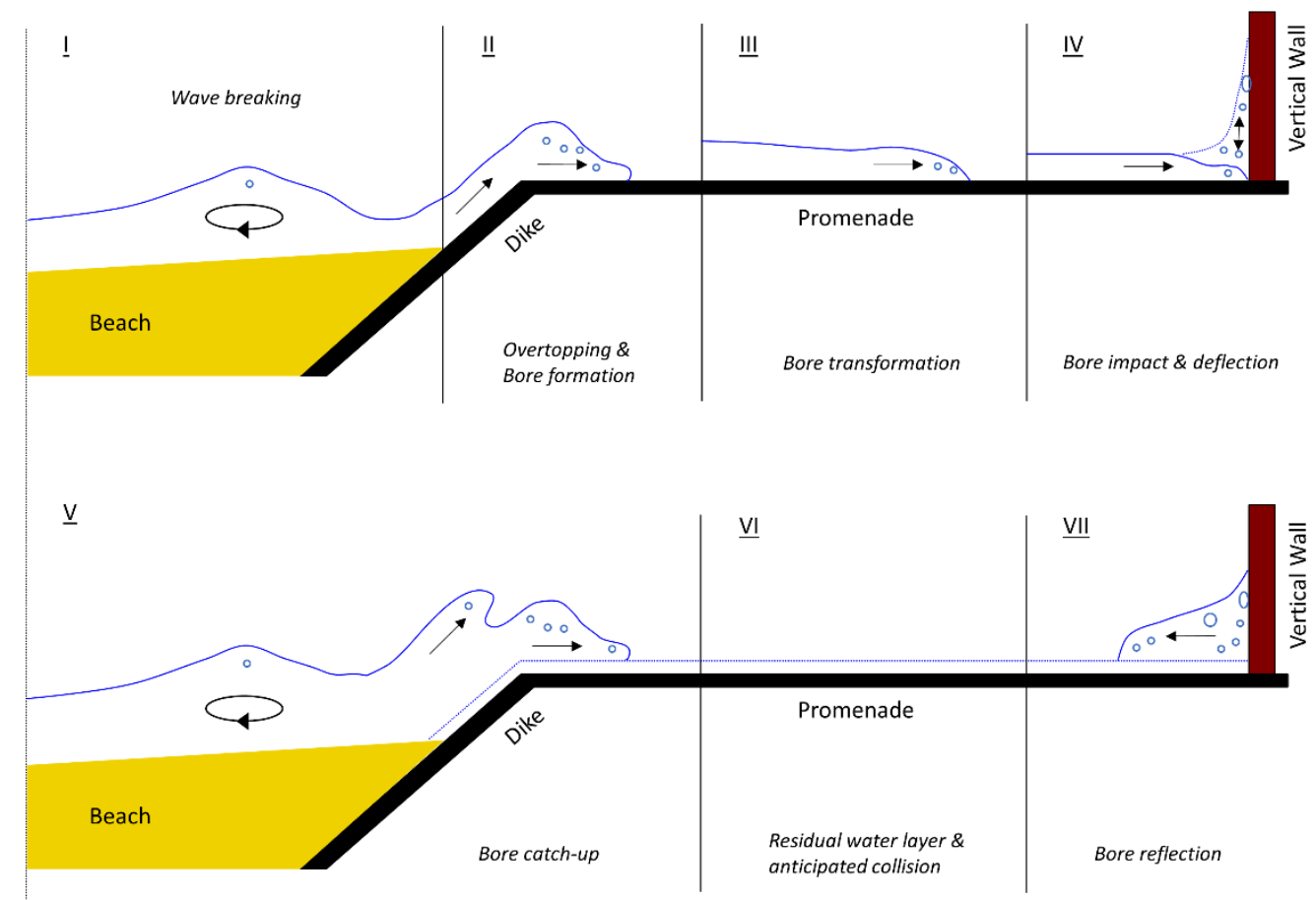

Figure 1: Process overview of overtopping bores impacting a vertical wall on top of a promenade. I) wave breaking, II) wave overtopping and formation of overtopping bore, III) transformation of bore along promenade, IV) initial impact at the wall and upward deflection, V) wave catch-up and VI) sequential overtopping, VII) anticipated collision of incoming and reflected bore

signal. To give a comprehensive overview of existing semi-empirical force prediction formulae four main criteria were distinguished. 1) which formula input parameters were used, e.g. bore velocity of incoming flow. 2) whether the fitting data was derived from small- or large-scale experiments, with the latter being less distorted by scale effects due to the entrained air. 3) which geometrical set-up was used, e.g. mild foreshore, dike, flat bottom, and 4) which wave conditions, e.g. Tsunami bore, irregular, regular waves were tested. Because the different formulae used varying symbol conventions, the formulae were adapted using the same naming convention. $\eta[\mathrm{m}]$ was the time-varying bore thickness on the promenade, $\mathrm{u}[\mathrm{m} / \mathrm{s}]$ the time-varying bore velocity on the promenade, $g=9.81\left[\mathrm{~m} / \mathrm{s}^{2}\right]$ the acceleration due to gravity, and $\rho_{\mathrm{w}}$ was the density of water approximated as $1000 \mathrm{~kg} / \mathrm{m}^{3}$. Previously, the analogy was made between an overtopping wave and a Tsunami bore (Chen et al. 2015) or an overtopping wave and a tidal bore (Lubin \& Chanson 2017). Even though the Tsunami bore had a much longer duration ( $~ 80 \mathrm{~s}$ or longer in prototype) compared to typical overtopped wave durations $(\sim 0.5-3 \mathrm{~s}$ in prototype), the initial impact, first force peak $F_{1}$, was expected to follow the same physical process, since both bore types display a turbulent and foamy bore front with air entrained in the bore. Therefore empirical and semi-empirical approaches to predict tsunami bore impacts were included in this review as well. An early approach to predict the dynamic impact of an overtopped water wedge against a wall was theoretically derived by Cumberbatch (1960) for incompressible, inviscid fluid and irrotational flow without the effects of gravity. Cross (1967) showed that this theoretical approach could be interpreted using laboratory data and by adding a hydrostatic force term (Equation 1). He also introduced the bore front slope $\theta_{0}$ as a parameter to calculate the impact force related to the incoming bore flow parameters (Equation 2).

$$
\begin{gathered}
F=\frac{1}{2} \cdot \rho_{w} \cdot \mathrm{g} \cdot \eta^{2}+C_{f} \cdot \rho_{w} \cdot \eta \cdot u^{2} \\
C_{f}=\tan \left(\theta_{0}\right)^{2}+1
\end{gathered}
$$


The bore front slope ranged between $0^{\circ}$ and $75^{\circ}$. Experiments with bores resulting from broken solitary waves on 1-to-50 slope wet bed situations were carried out by Ramsden (1996). He adapted the approach by Cross (1967) for the bore impact force against a wall (Equation 3):

$$
\mathrm{F}=\frac{1}{2} \cdot \rho_{w} \cdot \mathrm{b} \cdot(\eta+\mathrm{h})^{2}+\rho_{w} \cdot \mathrm{b} \cdot \eta \cdot u^{2} \quad[N]
$$

where $\mathrm{b}[\mathrm{m}]$ was the building width and $\mathrm{h}[\mathrm{m}]$ the initial water level before arrival of the bore. The dry bed surge impact force can thus be calculated by simply excluding the variable h. Asakura et al. (2002) developed an empirical formulation for the tsunami impact force derived from experiments on a mild sloping foreshore and a vertical wall (Equation 4). The maximum force was only dependent on three times the layer thickness in front of the wall squared.

$$
F_{\max }=\frac{1}{2} \cdot \rho_{w} \cdot g \cdot(3 \cdot \eta)^{2} \quad[N]
$$

Based on the findings from Asakura et al. (2002) an experimental test campaign on the same set-up excluding the vertical wall was carried out by Robertson et al. (2011). The incoming and unobstructed bore flow parameters, thickness $\eta[\mathrm{m}]$ and velocity $u[\mathrm{~m} / \mathrm{s}]$, were related to the maximum bore impact force and an empirical best-fit equation was derived (Equation 5).

$$
F=\frac{1}{2} * \rho_{w} * g * \eta^{2}+\rho_{w} * \eta * u^{2}+\rho_{w} * g^{1 / 3} *(\eta * u)^{4 / 3} \quad[N]
$$

Recently, tsunami impacts on storm walls were researched by Kihara et al. (2015). They noticed that the pressure distribution at the wall changes from dynamic to more quasi-steady state ( $>5 \mathrm{~s}$ ) over the duration of the impact. In quasi-steady state an almost hydrostatic pressure distribution occurred over the wall height, dependent only on the bore depth in front of the wall (for $\eta>1.5 \mathrm{~m}$ ). The maximum force peak was then the hydrostatic force or the integrated pressure over the run-up height (Equation 6).

$$
F_{\max }=\frac{1}{2} \cdot \rho_{w} \cdot \mathrm{g} \cdot \eta_{\max }^{2}
$$

Additionally, a variety of drag-force-based approaches in the field of tsunami impact research existed for dry bed surges and wet bed bores (Wütherich et al. 2017, Fujima et al. 2009, Yeh et al. 2006, Arnason et al. 2005, FEMA 2000, Ramsden 1993). They approximated the maximum bore impact force using a variation of the Morrison equation, neglecting the inertia term, and thus focusing on the drag force term of the bore flow (Equation 7). In Equation 7 the density of water $\rho_{\mathrm{w}}$ is approximated as $1000 \mathrm{~kg} / \mathrm{m}^{3}$, the building width is $b[\mathrm{~m}]$ and depth average bore velocity is $u[\mathrm{~m} / \mathrm{s}]$.

$$
F_{\max }=C_{D} \cdot \rho_{w} \cdot \mathrm{b} \cdot\left(\eta \cdot u^{2}\right)_{\max } \quad[N]
$$

To be physically correct a constant flow around the structure (building) was assumed with a certain bore flow thickness $\eta[\mathrm{m}]$ and velocity $\mathrm{u}[\mathrm{m} / \mathrm{s}]$. Often flow thickness $\eta$ and velocity u were measured without the structure present, assuming that a maximum momentum flux would yield in the maximum impact force (Wüthrich et al. 2017). The drag coefficient $C_{D}$ or often termed resistance coefficient $C_{r}$ in these studies was the variable parameter between these approaches (Table 1). A coefficient $C_{r}=2$ (hydrodynamic force) or 3 (maximum surge force) was used. Hydrodynamic force was thereby the force of the developed flow on the structure and maximum surge force the force of the initially impacting flow on the structure.

\begin{tabular}{|l|l|c|l|l|l|l|}
\hline \multicolumn{6}{|c|}{ Table 1: Drag/ resistance coefficients $\mathbf{C}_{\mathrm{D}}, \mathbf{C}_{\mathrm{r}}$ to approximate the maximum tsunami impact force on buildings } \\
\hline & $\begin{array}{l}\text { Wüthrich et al. } \\
(2017)\end{array}$ & $\begin{array}{l}\text { Yeh et al. } \\
(2006)\end{array}$ & $\begin{array}{l}\text { Arnason et al. } \\
(2005)\end{array}$ & $\begin{array}{l}\text { Fujima et al. } \\
(2009)\end{array}$ & $\begin{array}{l}\text { FEMA Ch. 8 } \\
(2000)\end{array}$ & $\begin{array}{l}\text { Ramsden } \\
(1993)\end{array}$ \\
\hline $\mathrm{C}_{\mathrm{D}}, \mathrm{C}_{\mathrm{r}}$ & 2 & 3 & 3 & $\sim 1$ & 2 & 3 \\
\hline
\end{tabular}


While the experiments of Wüthrich et al. (2017) were conducted for dry bed bores travelling on flat horizontal surfaces, the experiments from Fujima et al. (2009) involved a 1-in-3 dike slope and a promenade with a vertical wall at the end. The situation for storm walls, with no flow around the structure, was not entirely the same as for tsunami bore impacts on buildings with small widths. The buildings were relatively narrow compared to the long-crested tsunami bores. Therefore, the empirical impact predictions derived for structures with dry backsides (Kihari et al. 2015, Robertson et al. 2011, Asakura et al. 2002, Cross, 1967) were of major interest due to their geometrical similarity to this study. Furthermore, Tanimoto et al. (1984) predicted the first force peak as 3.3 times the second force peak. Another upper limit for the first force peak caused by a tsunami bore was introduced by Ramsden (1993) and Arnason (2005) as $150 \%$ of the subsequent hydrodynamic force of the quasi-steady flow.

\begin{tabular}{|c|c|c|c|c|c|c|}
\hline Author & Equation & $\begin{array}{l}\text { Model } \\
\text { scale }\end{array}$ & Geometry & Waves & $\begin{array}{c}\text { Input } \\
\text { parameter }\end{array}$ & Impact type \\
\hline Cross (1967) & Eq. 1 & small & flat bottom, wall & Tsunami bore & $\eta, u, \theta$ & Dynamic \\
\hline Ramsden (1993) & Eq. 3 & small & $\begin{array}{l}\text { mild foreshore, } \\
\text { building }\end{array}$ & wet bed bore & $\eta, h, c, b$ & Dynamic \\
\hline $\begin{array}{l}\text { Asakura et al. } \\
(2002)\end{array}$ & Eq. 4 & small & $\begin{array}{l}\text { mild foreshore, } \\
\text { wall }\end{array}$ & Tsunami bore & $\eta$ & Dynamic \\
\hline $\begin{array}{l}\text { Robertson et al. } \\
(2011)\end{array}$ & Eq. 5 & small & $\begin{array}{l}\text { mild foreshore, } \\
\text { wall, no wall }\end{array}$ & Tsunami bore & $\eta, u$ & Dynamic \\
\hline Kihari et al. (2015) & Eq. 6 & large & flat bottom, wall & Tsunami bore & $\mathrm{R}_{\mathrm{h}}$ & Quasi-static \\
\hline Drag force & Eq. 7 & small & $\begin{array}{l}\text { flat bottom, } \\
\text { building }\end{array}$ & $\begin{array}{l}\text { Tsunami wet } \\
\text { bed bore and } \\
\text { dry bed surge }\end{array}$ & $\eta, u$ & Dynamik \\
\hline Chen et al. (2012) & Eq. 8 & small & $\begin{array}{l}\text { mild foreshore, } \\
\text { dike, promenade, } \\
\text { wall }\end{array}$ & regular waves & $\mathrm{R}_{\mathrm{h}}$ & Quasi-static \\
\hline $\begin{array}{l}\text { Van Doorslaer et } \\
\text { al. (2012) }\end{array}$ & Eq. 11 & large & $\begin{array}{l}\text { overtopping } \\
\text { simulator, } \\
\text { promenade, wall }\end{array}$ & $\begin{array}{l}\text { overtopping } \\
\text { volumes }\end{array}$ & $\eta, u$ & Dynamic \\
\hline $\begin{array}{c}\text { Van Doorslaer et } \\
\text { al. (2016) }\end{array}$ & Eq. 13 & large & $\begin{array}{l}\text { dike, promenade, } \\
\text { wall }\end{array}$ & $\begin{array}{l}\text { irregular } \\
\text { waves }\end{array}$ & $\eta, u, R_{c}$ & Dynamic \\
\hline
\end{tabular}

A number of studies were conducted on similar geometries (mild foreshore, dike) to the geometrical setup of the present study using short duration ( 0.5 - $3 \mathrm{~s})$ overtopped wave impacts. They were divided into studies which derived an individual force F (Van Doorslaer et al. 2016, Chen et al. 2012, Van Doorslaer et al. 2012) or an averaged force such as $F_{1 / 250}$ based on averaged test parameters (Van Doorslaer et al. 2016, Chen et al. 2016, Chen et al. 2015, Kortenhaus et al. 2015, Ramachandran et al. 2012, De Rouck et al. 2012, Verwaest et al. 2011, Allsop 2005, Kleidon 2004, Den Heijer et al. 1998). The latter studies lack prediction capability for individual overtopped bore impacts, and thus, were not evaluated in this study. Hence, only formulae predicting an individual bore impact force were further investigated. For regular waves and a variable wall location, a study was conducted in a small-scale experimental set-up (Chen et al. 2012). Based on momentum flux theory they were able to predict the second force peak solely dependent on the maximum run-up height $R_{h}$ of the water at the wall. The runup height was measured by a wave gauge installed $1.5 \mathrm{~cm}$ in front of the wall. The coefficient $\mathrm{C}_{1}=0.30$ was defined as a substitute for the unknown bore front angle in the momentum flux theory (Equation 8 ).

$$
F_{\max }=C_{1} \cdot \rho_{w} \cdot \mathrm{g} \cdot R_{h, \max }^{2} \quad\left[\frac{\mathrm{N}}{\mathrm{m}}\right]
$$

In a different approach the wave overtopping simulator (Van der Meer et al. 2010) was used to simulate an overtopping bore by releasing a defined volume of water $(500 \mathrm{l} / \mathrm{m}$ per s up to $5000 \mathrm{l} / \mathrm{m}$ per s) on to a $10 \mathrm{~m}$ wide promenade and measure the impact force of the bore flow against two measurements plates installed at the end of the promenade (Van Doorslaer et al. 2012). Additionally, bore flow thicknesses $\eta$ $[\mathrm{m}]$ and velocities $u[\mathrm{~m} / \mathrm{s}]$ were measured by means of a potentiometer and paddle wheels attached to a surf board floating on the water. Only the results for a non-overtopped vertical measurement plate were evaluated (Equation 9). 


$$
F_{\text {max }}=1.09 \cdot u+52.1 \cdot \eta-9.5 \quad\left[\frac{\mathrm{N}}{\mathrm{m}}\right]
$$

Large-scale experiments were conducted in the GWK Hannover for a set-up with deeper water at the dike toe, $10 \mathrm{~m}$ wide promenade and wall at the end of the promenade (Van Doorslaer et al. 2016). Bore thickness $\eta[\mathrm{m}]$ was measured in the vicinity of the wall by means of wave gauges, and the bore front velocity was estimated as the distance between wave gauge and wall divided by the bore travel time. After applying a selection routine to detect discrete overtopping events, 621 impacts in the lower range were used to derive an empirical equation for the impact force (Equation 10).

$$
\mathrm{F}_{\max }=\rho \cdot \mathrm{g} \cdot R_{c}^{2} \cdot 0.4 \cdot \exp \left(\frac{(u \cdot \eta)_{\max }}{\sqrt{g \cdot R_{c}^{2}}}\right)^{1.313} \quad\left[\frac{N}{m}\right]
$$

where $R_{c}$ is the freeboard, defined as the distance between the still water level and the top of the wall at the end of the promenade. They noticed that the instantaneous discharge as the product of bore thickness $\eta$ and velocity $u$ is a better estimator of the maximum impact force than one of the two parameters studied individually. Also, they stated that the maximum instantaneous discharge decreased by $30 \%$ over the $10 \mathrm{~m}$ width of the promenade

\section{Objectives and Methodology}

The Belgian coastal geometry is often comprised of a mildly sloping foreshore, dike, promenade and wall or building on top of the promenade. With overtopping waves traversing across the dike crest, an impact is generated on these buildings or walls. Prediction formulae for this kind of impact should 1) account for this specific geometry, 2) be based on a data-set featuring irregular waves to allow for the realistic wave-wave interaction processes prior to impact, and 3) the prediction formulae should be based on large-scale data to avoid scale effects (e.g. air entrainment). Existing semi-empirical formulae to predict the maximum impact force were evaluated from related literature. As can be seen from Table 2, none of the existing formulae fulfill all 3 criteria at the same time. The formulae were derived based on different experiment set-ups, different variable input parameters and different wave types. Hence, detailed objectives of this study were:

1. to study the overtopped wave impact process for irregular and broken waves in shallow water and mild foreshore conditions based on large-scale experimental data

2. to distinguish the physical processes leading to maximum first $F_{1}$ and second $F_{2}$ force peak in the twin peaks impact signal shape

3. to adapt existing and derive new semi-empirical formulae to predict the maximum first $\mathrm{F}_{1}$ and second $F_{2}$ force peak, which are in agreement with the underlying physics

For this purpose the impact process leading to the first $F_{1}$ and second $F_{2}$ force peak was investigated using large-scale experimental data from a test conducted on a geometry similar to coasts of low-lying countries. The 60 highest force peaks from two tests featuring wave conditions similar to a 1-in-1000 and 1-in-17000 storm return interval were selected. The existing prediction formulae were tested using these 60 highest force peaks. Additionally, the momentum flux and hydrostatic theory were fitted to the data for the first $F_{1}$ and second $F_{2}$ force peaks respectively. The goodness of fit parameters were evaluated and the prediction accuracy discussed.

\section{DATA-SET}

Model tests were conducted in March 2017 in the Delta Flume in Delft, The Netherlands, as part of the research project WALOWA (WAve LOads on WAlls), carried out within the EU programme Hydralab+. A detailed model and measurement set-up was provided by Streicher et al. (2017). Hereafter, only a compact overview of geometry, measurement set-up and analysis methods has been summarized.

\section{Model geometry set-up}

The model geometry was a scaled representation of a large part of the bathymetry and topography of coasts from low-lying countries. The Froude length scale factor was 4.3-to-1. A sandy foreshore with a transition slope $\cot \left(\theta_{1}\right)=10$ at the beginning and continuing with a $\cot \left(\theta_{2}\right)=35$ foreshore slope until seaward of the toe of the dike. The distances of the transition and main foreshore slope were $19.5 \mathrm{~m}$ and $61.6 \mathrm{~m}$, respectively. The total foreshore volume was comprised of $\sim 1000 \mathrm{~m}^{3}$ of sand spread over the 5- 
$m$ flume width. Attached to the foreshore was a concrete dike with a slope of $\cot (\alpha)=2$. The dike height was $0.53-\mathrm{m}$. Landward of the dike crest seaward edge was a $2.35-\mathrm{m}$-wide promenade, and at the landward end of the promenade a vertical 1.6-m-high steel wall was built. The overtopped bore impacts were measured at the vertical wall. Waves were generated by a piston-type wave paddle at the one end of the flume, and active wave absorption was used.

\section{Measurement set-up and data processing}

The measurement set-up was divided into 3 measurement groups. First measurement group consisted of the water surface elevation $\eta(\mathrm{t})[\mathrm{m}]$ measurements to obtain the spectral wave parameters $\mathrm{T}_{\mathrm{m}-1,0}[\mathrm{~s}]$ and $\mathrm{H}_{\mathrm{m} 0}[\mathrm{~m}]$, as they are typically key parameters for the design of coastal structures. The second measurement group included the overtopping bore thickness $\eta(t)[\mathrm{m}]$ and velocity $u(t)[\mathrm{m} / \mathrm{s}]$ measurement on top of the promenade. The third measurement group consisted of the impact measurement of forces $\mathrm{F}(\mathrm{t})[\mathrm{kN} / \mathrm{m}]$ and pressures $\mathrm{P}(\mathrm{z}, \mathrm{t})$ [bar] of the overtopped water against the wall. All measurements were sampled at $1000 \mathrm{~Hz}$ frequency and synchronized in time. For the purpose of this study two irregular wave tests with approximately 1000 waves each were selected (Table 3). TestID Irr_1_F represented a storm with a return interval of 1-in-17000 years and testID Irr_4_F a storm with 1-in-1000 year return interval.

\section{Wave and Water Level Parameters}

The water surface elevation $\eta(t)$ was measured with inhouse-developed resistive types wave gauges deployed at the right flume wall, when looking towards the paddle. Wave gauges 2-4 were installed in the flat bottom part of the flume close to the wave paddle to measure the deep-water surface elevation. These wave gauges allowed for reflection analysis of the signal using the method of Mansard and Funke (1980). Wave gauge 14 was installed $0.35 \mathrm{~m}$ seaward of the dike toe. The indices 'o' and ' $\mathrm{t}$ ' were used to refer to the measurement location at the offshore location (above the flat bottom part in the flume, before the start of the foreshore) and at the dike toe ( $\mathrm{X}=175.08 \mathrm{~m}$ from the paddle) respectively. Spectral wave parameters at the deep water location $\mathrm{H}_{\mathrm{m} 0_{-} \mathrm{o}}[\mathrm{m}]$ and $\mathrm{T}_{\mathrm{m}-1,0_{-} \mathrm{o}}[\mathrm{s}]$ were obtained after reflection analysis. The incident spectral wave parameters at the dike toe were determined with SWASH calculations (Streicher et al. 2017). As expected, the wave height decreased by a factor of $3.5-4.0$ due to wave breaking and loss in energy on the mild foreshore; and the spectral wave period increased by a factor of $2.1-2.2$ due to the release of the bound long waves in the breaking process on the mild foreshore (Hofland et al. 2017). The offshore breaker parameter indicated spilling wave breaking, typical for mild foreshores and the wave steepness at the dike toe < than 0.01 often means that the waves were broken due to depth limitations (Eurotop 2016). The water depths at the dike toe were considered extremely shallow (Hofland et al. 2017). The according freeboards Ac, distance between SWL and the height of the promenade, ranged between $0.27 \mathrm{~m}$ and $0.47 \mathrm{~m}$.

Table 3. Storm wave and water level conditions for testID Irr_1_F and Irr_4_F of the WALOWA test campaign.
Storm return periods were 17000 and 1000 years respectively (Values in model scale).
\begin{tabular}{|c|c|c|c|c|c|c|c|c|c|c|c|}
\hline testID & Waves & $\mathrm{h}_{\mathrm{o}}$ & $\mathrm{h}_{\mathrm{t}}$ & $\mathrm{A}_{\mathrm{c}}$ & $\mathrm{H}_{\mathrm{m} 0,0}$ & $\mathrm{H}_{\mathrm{m} 0, \mathrm{t}}$ & $\mathrm{T}_{\mathrm{m}-1,0, \mathrm{o}}$ & $\mathrm{T}_{\mathrm{m}-1,0, \mathrm{t}}$ & $\mathrm{S}_{\mathrm{m}-1,0, \mathrm{t}}$ & $\beta_{\mathrm{o}}$ & $\mathrm{h}_{\mathrm{t}} / \mathrm{H}_{\mathrm{m} 0, \mathrm{o}}$ \\
\hline- & - & $\mathrm{m}$ & $\mathrm{m}$ & $\mathrm{m}$ & $\mathrm{m}$ & $\mathrm{m}$ & $\mathrm{S}$ & $\mathrm{s}$ & - & - & - \\
\hline Irr_1_F & $\sim 1000$ & 3.99 & 0.28 & 0.27 & 1.05 & 0.30 & 5.8 & 12.3 & 0.0014 & 0.2 & 0.27 \\
Irr_4_F & $\sim 1000$ & 3.79 & 0.08 & 0.47 & 0.87 & 0.22 & 5.4 & 12.1 & 0.0012 & 0.2 & 0.09 \\
\hline
\end{tabular}

\section{Overtopping Flow Depth and Velocity}

The overtopping bore parameters thickness $\eta(\mathrm{t})$ and velocity $\mathrm{u}(\mathrm{t})$ were measured by instruments attached to a wooden frame installed $1 \mathrm{~m}$ above of the promenade on the right flume side when looking towards the paddle. Bore thickness measurements $\eta(t)$ were obtained by 4 resistance-type wave gauges (WLDM1 - WLDM4). The wave gauge foot with the reference electrode was submerged $5 \mathrm{~cm}$ below the elevation of the promenade, in a $12 \mathrm{~cm}$ deep bucket of water. Bore velocity measurements $\mathrm{u}(\mathrm{t})$ were obtained by 4 Airmar flow meter paddle wheels (PW1 - PW4), measuring only the incoming flow velocity. The paddle wheels were measuring the flow velocity $\mathrm{u}(\mathrm{t}) 0.03 \mathrm{~m}$ above the promenade. Both types of instruments (WLDM and PW) were installed in two lines parallel to the flume wall $0.24 \mathrm{~m}$ apart and roughly $0.5 \mathrm{~m}$ from the flume side wall. The measurements of WLDM3 and PW3 were used from $1.26 \mathrm{~m}$ apart of the dike crest and $1.09 \mathrm{~m}$ in front of the steel wall. The measurements at this location were less affected by the overtopping splash and the reflected bore from the wall. Detailed locations of the measurement devices measuring the bore parameters on the promenade can be found in Cappietti et al. (2018). The time-series of paddle wheels $\mathrm{PW} u(\mathrm{t})$ were filtered with a $15 \mathrm{~Hz}$ low-pass filter and the time-series of the 
layer thickness gauges WLDM $\eta(\mathrm{t})$ were not further processed (Figure 2). The maximum flow thickness $\eta_{\max }$ and flow velocity $\mathrm{u}_{\max }$ were manually read from the WLDM3 and PW3 signal for each of the overtopping bores associated with one of the 60 highest impacts. The measured maximum bore thicknesses and velocities ranged between $\eta_{\max }=0.02-0.42 \mathrm{~m}$ and $\mathrm{u}_{\max }=0.62-4.13 \mathrm{~m} / \mathrm{s}$ respectively (model scale).
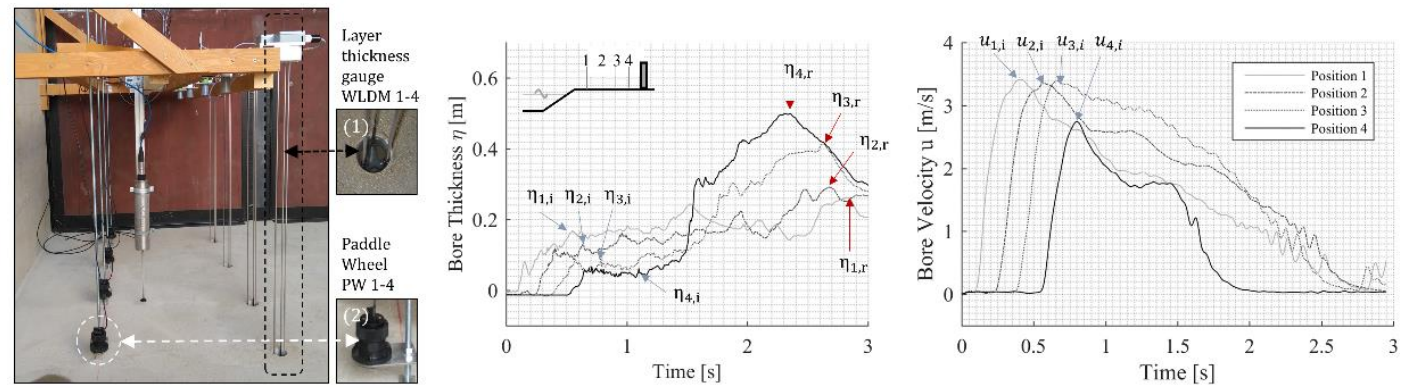

Figure 1: Measurement set-up of paddle wheels and layer thickness gauges (left). Time series of layer thickness gauges with incoming $\eta_{\mathrm{i}}$ and reflected $\eta_{\mathrm{r}}$ bore thickness measured at Position 1-4 (middle). Measured incoming bore velocity $\mathrm{u}_{\mathrm{i}}$ at Position 14 (right).

\section{Run-up at Wall}

The instantaneous run-up $R_{h}$ of the impacting bore at the wall was determined using GoPro ${ }^{\circledR}$ video images from a side-mounted and top-mounted camera and motion tracking of the leading edge of the run-up water body. The GoPro videos were recorded at $59.94 \mathrm{fps}$, a resolution of $2.7 \mathrm{k}(2704 \mathrm{px} * 1520 \mathrm{px})$ and synchronized with the force and pressure measurement, via a LED pulse visible in the camera images. The images from the overview camera were used to track the leading edge of the run-up bore at the wall and the images from the side view camera were used to judge whether or not the run-up water was in visible contact with the wall or had become separated because of reflection from the wall. Only the area which was in visible contact with the wall was used to calculate the instantaneous run-up height. The spatial resolution in the GoPro images depends on the distance and angle of the GoPro from the wall, and the resolution was always smaller than $0.002 \mathrm{~m}$ in all images. The standard deviation of the maximum run-up between repeated tracking of the same test was in the order of $\sigma=0.03 \mathrm{~m}$. The run-up was obtained on a line parallel to the pressure sensor array on the metal plate. Then the leading edge of the bore during the entire image sequence of impact and run-up was tracked and in this way the run-up at the wall was obtained. The method of tracking the run-up leading edge in combined overview and sideview video images gave higher spatial resolution, and it was preferred over obtaining the run-up, e.g. by using the highest pressure sensor that was showing an impact pressure in the wall. The measured maximum run-up heights ranged between $R_{h, \max }=0.20-1.59 \mathrm{~m}$ (model scale).

\section{Impact Force at Wall}

The impacts at the wall were measured by 15 Kulite HKM-379 (M) pressure sensors with a measurement range of $100 \mathrm{kPa}$. The pressure sensors were mounted in vertical and horizontal arrays on a metal plate. The metal plate was flush-mounted into a prefabricated opening in the middle section of the steel wall. The time-series of $\mathrm{P}(\mathrm{z}, \mathrm{t})$ was 1) filtered, 2) integrated over the run-up height, and 3 ) the maximum force peaks were detected using Matlab® software. In the first step filtering of the measured pressure signals was done. This involved removing drift and applying zero-offset corrections to the measured signal. The filtering was done in frequency domain. A low-pass Butterworth filter $2^{\text {nd }}$ order at $48 \mathrm{~Hz}$ was used. The low-pass filter was chosen as a compromise between preserving the short duration impulsive impacts and limiting the decrease in peak impact force, while filtering out the noise from the electronic current system (at $50 \mathrm{~Hz}$ ). In the second step rectangular pressure integration over the height of the pressure array was done to obtain a total horizontal force value per meter width. The third and last step involved selecting the key events from the resulting integrated force time-series, namely indicating the individual and independent maximum force peak for each impact (Figure 3, blue circles). A minimum time between force peaks was set to $2 \mathrm{~s}$. Additionally, a high-pass threshold for the peaks was set as low as the noise level of the measurement would allow at $0.005 \mathrm{kN} / \mathrm{m}$. 


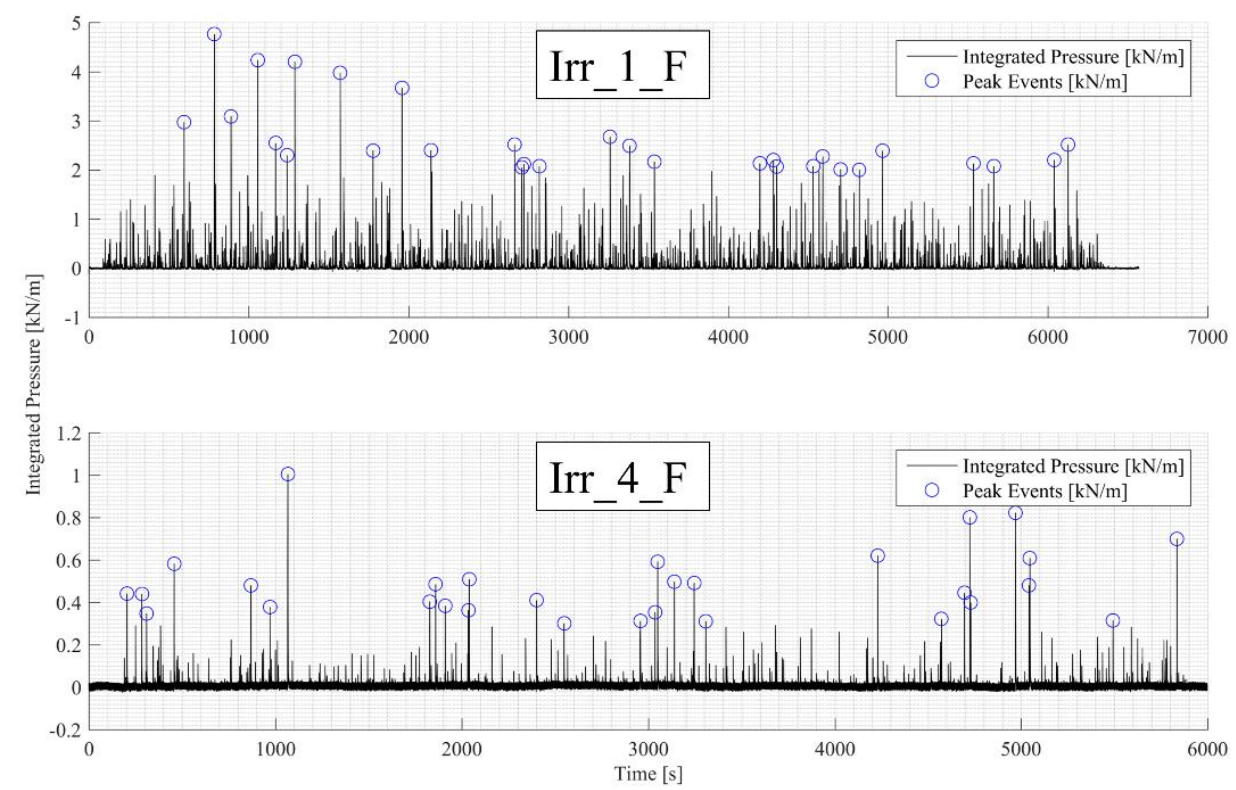

Figure 3: Filtered time-series of integrated pressures [kN/m] for testID Irr_1_F (top) and Irr_4_F (bottom). The selected 30 highest force peaks from each tests are highlighted with a blue circle.

The analyses in this study included only the highest impacts in both tests. Consequently, 30 highest impacts from each test, according to the integrated pressure signal, were selected. This resulted in 60 individual maximum impacts. Individual analysis of the highest impacts was considered more important for the purpose of formulating practical design guidance on maximum impacts, rather than further increasing the sample size. No further selection routine was applied. The large variation of incoming bore parameters, such as bore thicknesses and velocities, bore front slopes, bore impact process, bore interaction patterns were a good representation of the real phenomena and a challenge for processing the results.

\section{ANALYSIS AND DISCUSSION}

In the first phase of the analysis, the impact process was described and the moment of dynamic $F_{1}$ and quasi-static $\mathrm{F}_{2}$ force peak was highlighted. This was followed by evaluation and adaptation of prediction formulas for first $F_{1}$ and second $F_{2}$ force peaks..

\section{Impact Process}

Based on the integrated pressure signal and pressure distribution over the wall height, characteristics of the impact signal were examined. The combined evidence, of visual observation (Figure 4, left), measured total force (Figure 4, middle) and pressure distribution over the wall height (Figure 4, right), was used to study the impact process of the bore against the wall. Typically, the total horizontal force signal showed a double peak shape for each impact. While the first peak $F_{1}$ was related to the dynamic impact of the bore against the wall, the second peak $F_{2}$ was related to the run-up and down-rush of the bore after maximum run-up. In a few cases, a very short duration peak, with rise times $\mathrm{t}_{\mathrm{r}}=3 * 10^{-3}$ $1.2 * 10^{-2}$, was measured just when the bore tip impacted the wall. It was previously considered impulsive impact (Streicher et al. 2018), did not occur very often (9 out of 60 times), with very localized peak pressures and was thus not further investigated in this study.

After the initial impact of the bore tip with the wall, the continuous instream of water against the wall led to upward deflection of the water at the wall and an increase in measured total force and pressures over the wall height. Usually this resulted in the first force peak $F_{1}$ in the measured force signal (Figure 4a). The measured pressures over the wall height were of larger magnitude than the hydrostatic pressure based on the run-up at the wall. The pressure distribution was not linear but rather uniform from the bottom up to about the 0.23 - wall height. Above $0.23 \mathrm{~m}$ wall height the drop of pressures was more rapid with increasing height. It was assumed that the formation of two rollers in the impacting flow result in this particular pressure distribution (Kihari et al. 2015). The flow in this area formed a roller in counterclockwise direction (in reference to the sideview frame shown in Figure 2) resulting in the rapid 
pressure drop. Conversely, the flow formed a clockwise roller below $0.23 \mathrm{~m}$ wall height, resulting in downward acceleration in the lower part of the wall. Kihari et al. (2015) stated that the expected hydrostatic decrease was compensated by this downward accelerated part of the water body and led to a constant pressure distribution below $\mathrm{x}=0.23 \mathrm{~m}$ wall height. The dynamic effects based on incoming bore velocities and their change in direction were dominant over the hydrostatic effects at the moment of first impact $F_{1}$. Hence, the term dynamic force peak is used for the first peak $F_{1}$ in the impact force signal. The impact durations for dynamic impact types ranged between $t_{r}=0.1-0.6 \mathrm{~s}$. This was well in the range of natural periods, estimated to be in between $0.1-1 \mathrm{~s}$ for $3-50 \mathrm{~m}$ high buildings at the coast (Chen et al. 2016), and resonance effects should be considered for the dynamic impacts.
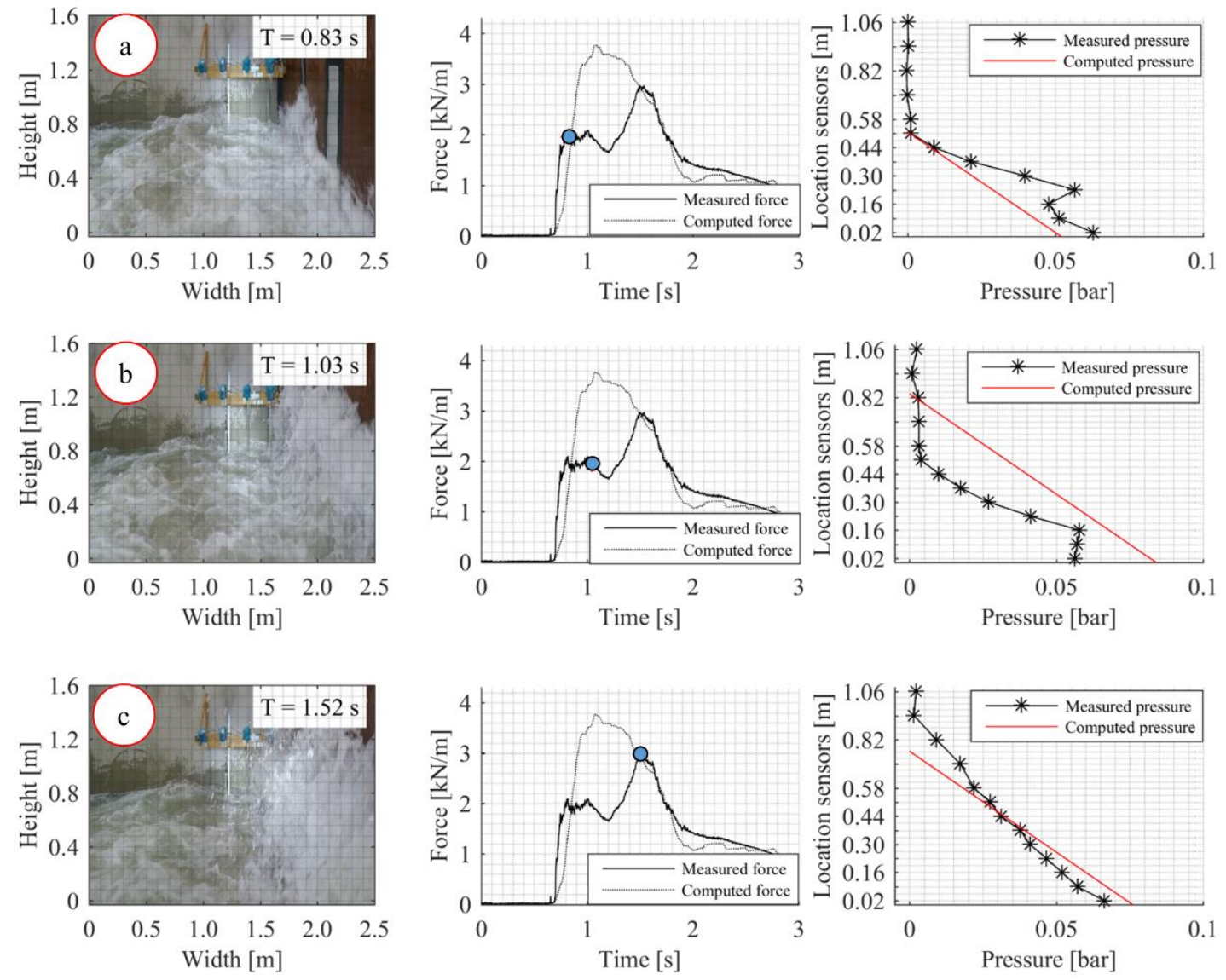

Figure 4: a) Moment of dynamic force peak $F_{1}$, b) maximum run-up $R_{h, m a x}$ and c) quasi-static force peak $F_{2}$. The sideview GoPro image (left), measured force and hydrostatic force estimated based on run-up (middle), measured pressure distribution and hydrostatic pressure distribution based on run-up (right).

After maximum dynamic force peak $\mathrm{F}_{1}$, the bore was continuously deflected upwards until it reached the moment of maximum run-up at the wall (Figure 4b). At the same time the measured pressures over the entire wall height were smaller than calculated assuming a hydrostatic pressure distribution. It was argued that the difference between the measured total horizontal force and the force calculated by assuming a hydrostatic pressure distribution at each run-up elevation arose due to upward acceleration of the water body in front of the wall and possible unweighing of the water body. After maximum run-up of the water body at the wall, the upper part of the water body collapsed; and due to blocking of the wall, outward reflection of the water body occurred (Figure 4c). A short time after the maximum run-up, the measured force slightly exceeded the hydrostatic force estimate. Also, the pressures in the upper part of the water body were larger than hydrostatic pressures based on the instantaneous run-up. This implied that there was an additional dynamic force component at work which resulted in the difference between the measured signals and theoretical hydrostatic estimates. This observation was supported by Ramsden and Raichlen (1990) who assumed that vertical accelerations were the cause for the time lag between maximum run-up and maximum second peak force peak $F_{2}$. Previously the second peak $F_{2}$ in the twin peak signal was attributed to the down-rush pressure of the collapsing water column after maximum run- 
up, and it is also termed reflecting pressure (Chen 2016, Streicher et al. 2016, Kihari et al. 2015, Ramsden 1996). Chen (2016) stated that the continuous instream of water led also to an increase of the measured force compared to the hydrostatic force estimate at the moment of the second peak $\mathrm{F}_{2}$. Despite this dynamic component, the authors decided to stick to the term quasi-static for the second peak $F_{2}$ in the impact signal because of the dominant hydrostatic effects. The small dynamic component was sufficiently considered by using the term "quasi" in the name. Hence, the term quasi-static force peak $F_{2}$ will be further used to refer to the second peak in the impact signal.

In 42 out of 60 impacts the quasi-static force peak $F_{2}$ was larger than the dynamic force peak $F_{1}$ (roughly $2 / 3)$ as well as the largest recorded impact $(F=4.77 \mathrm{kN} / \mathrm{m})$ was a quasi-static force peak $\mathrm{F}_{2}$. Nevertheless, the second largest impact was a dynamic force peak $F_{1}$.and generally the magnitude of impact did not differ much between dynamic $F_{1}$ and quasi-static $F_{2}$ force peaks. Hence, the double peak impact signal shape resembled more a twin peak signal profile rather than the previously described "church roof profile" (Oumeraci et al. 1993). Whereas Tsunami bore impacts ( 80 s or longer) reach a quasi-steady state a few seconds after main impact (Kihari et al. 2015), this was never really the case for the short duration $(\sim 0.5-3 \mathrm{~s})$ bore impacts examined in the present study. However, the total horizontal force calculated from pressure measurements converged with the hydrostatic force estimates towards the tail of the impact time series. Small undulations of the measured force occurred fluctuating around the hydrostatic force. They are most likely due to sway movements of the flow in front of the wall and slowly decreasing run-up height.

\section{Prediction of quasi-static impact force $F_{2}$}

As described in the previous section the hydrostatic force, a large mass of water statically subjected on the structure, was dominant in generating the quasi-static force peaks $F_{2}$. Hence, any existing formula (Table 2) taking into account the bore thickness directly in front of the wall, or run-up height of the bore at the wall were physically most correct (Equation 6, Equation 8, Equation 13). These equations were used to predict the quasi-static force $F_{2}$ using the maximum run-up height $R_{h \text {,max }}$ related to the 60 selected maximum impacts. The calculated result was compared to the according measured quasi-static $\mathrm{F}_{2}$ force peak (Figure 5). Froude scaling and a length scale factor 4.3 were used to compare calculated and measured impact force in prototype-scale units. The goodness of fit parameters, standard deviation $\sigma$ $(3.21 \mathrm{kN} / \mathrm{m}-6.31 \mathrm{kN} / \mathrm{m})$ and the mean absolute percentage error MAPE $(0.4432-0.9963)$ were
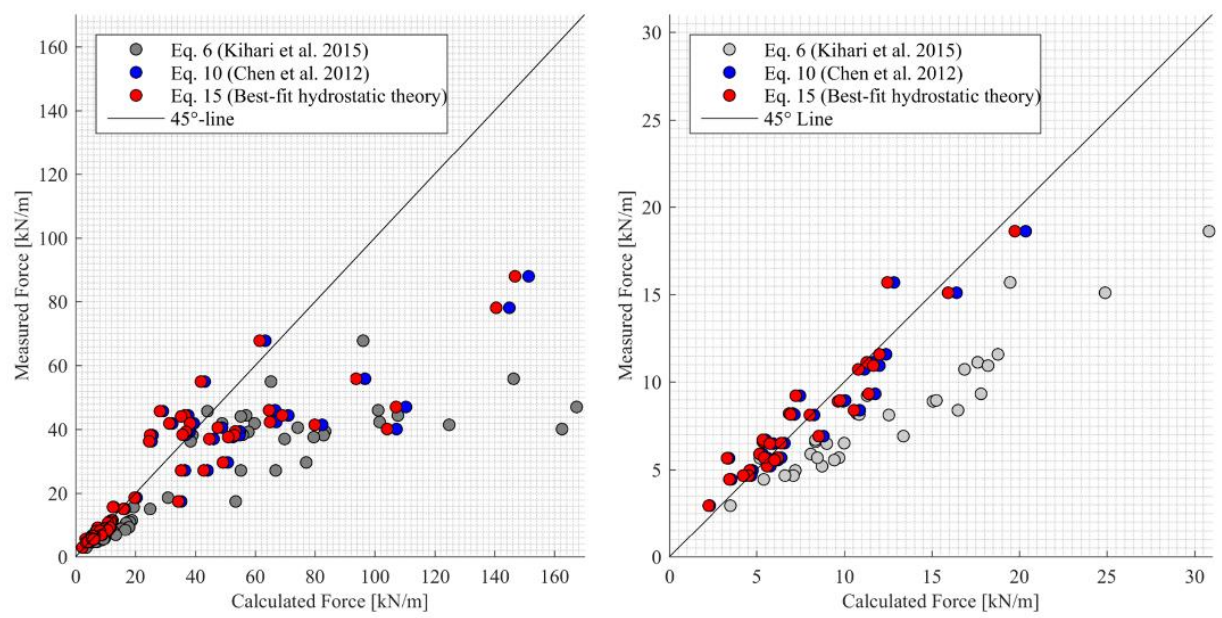

Figure 5: Empirical prediction formulas for the quasi-static force peak $\mathrm{F}_{2}$ for all force peaks (left) and a zoom on the smaller force peaks from test ID Irr_4_F resulting from a storm with a 1000 year return interval (right). Results are given in prototype using Froude scaling and the scaling factor 4.3 .

calculated (Table 4). The values given in brackets have to be treated carefully because these specific prediction results show a bias, leading to erroneous goodness of fit parameters. The MAPE error estimator was chosen over the coefficient of determination $\mathrm{R}^{2}$ for comparison, as it is less biased towards extreme outliers. Equation 6 (Kihari et al. 2015) tend to always over predict the impact force. This was expected because the equation was derived for a situation with developed tsunami overflow over the wall and a larger water body in front of the wall. Conversely, the run-up events in this study were derived for short duration overtopped bores with thin run-up tongues. 
For force peaks above $25 \mathrm{kN} / \mathrm{m}$ all formula over-predict the impact force. The over prediction was caused by the quadratic influence of the maximum run-up height $\mathrm{R}_{\mathrm{h}, \max }$ in front of the wall, leading to the conclusion that not the entire run-up height, especially for large run-up values, was effectively contributing to the quasi-static impact force. This was in line with previous studies stating that not all of the total run-up height was effectively contributing to the hydrostatic impact force (Klammer et al. 1996). It was also argued that the maximum run-up height had no direct physical connection to the quasi-static force peak $F_{2}$ as the maximum run-up occurred slightly before the quasi-static force peak $F_{2}$. This is why the reflected water mass (water body in front of wall after the collapse of maximum run-up) might be an even better approximation of the quasi-static force peak $F_{2}$.

Contrary to the assumption in the hydrostatic theory, the maximum run-up water body did not arise from a horizontal water surface in front of the wall, but rather a triangular shape of run-up flow. This resulted in a lower effective water mass contributing to the hydrostatic force, especially for larger run-up heights with even thinner run-up tongues in the upper part. Linear regression and fitting of the force peaks to the hydrostatic theory was done using the maximum run-up height $\mathrm{R}_{\mathrm{h} \text {,max }}$ obtained from motion tracking of the bore front at the wall. The fitting was done for force peaks up to $25 \mathrm{kN} / \mathrm{m}$ and by minimizing the MAPE error and a best-fit equation obtained (Equation 13).

$$
\begin{gathered}
F_{\text {Best-fit }}=\frac{1}{2} \cdot \rho_{w} \cdot g \cdot\left(C \cdot R_{h, \text { max }}\right)^{2} \quad\left[\frac{\mathrm{N}}{\mathrm{m}}\right] \\
C=0.8 \quad[-] \\
F_{\text {Best-fit }}=0.32 \cdot \rho_{w} \cdot g \cdot R_{h, \text { max }}^{2} \quad\left[\frac{\mathrm{N}}{\mathrm{m}}\right]
\end{gathered}
$$

Based on these findings it was stated that only a $80 \%$ of the maximum run-up $\mathrm{R}_{\mathrm{h} \text {,max }}$ was effectively contributing to the impact force on the wall. Substituting Equation 12 into Equation 11 yields in a coefficient of 0.32 , which was very close to what was found earlier as $\mathrm{C}_{1}=0.30$ by adapting the momentum flux theory and using regular waves (Chen et al, 2012). Hence, this finding served as a largescale confirmation that the prediction of quasi-static force peaks $\mathrm{F}_{2}$ using $80 \%$ of the maximum run-up height was also valid for irregular waves. For practical design guidance and determining the overturning moment of sea-walls, Equation 13 can also be used inversly to calculate the $80 \%$ maximum run-up height based on any given force.

\begin{tabular}{|c|c|c|c|c|}
\hline \multicolumn{5}{|c|}{ Table 4. Quasi-static impact type $\mathbf{F}_{\mathbf{2}}$ prediction formulae with goodness of fit parameters (prototype values) } \\
\hline \multicolumn{1}{|c|}{ Author } & Equation & $\sigma$ & $\mathrm{R}^{2}$ & MAPE \\
\hline- & - & $\mathrm{kN} / \mathrm{m}$ & - & - \\
\hline Kihari et al. (2015) & Eq. 6 & 6.31 & $(3.6059)$ & $(0.4432)$ \\
\hline Chen et al. (2012) & Eq. 8 & 3.38 & 0.2061 & 0.9725 \\
\hline Best-fit hydrostatic theory & Eq. 13 & 3.23 & 0.2943 & 0.9963 \\
\hline
\end{tabular}

\section{Prediction of dynamic impact force $F_{1}$}

As described in the previous section the bore thickness and velocity were important during the impact mechanism leading to the dynamic force peak $F_{1}$. Hence, any existing formula (Table 2) taking into account the incoming bore thickness and bore velocities prior to impact were considered physically most correct. Equation 1, Equation 3, Equation 4, Equation 5, Equation 7 were evaluated from the tsunamirelated research; and Equation 9, Equation 10, Equation 13 were evaluated from the overtopping waverelated research studies. The dynamic force peak $F_{1}$ for each of the proposed formulas was calculated based on the maximum bore thickness $\eta_{\max }$ and maximum bore velocity $u_{\max }$ immediately prior to the dynamic force peaks $F_{1}$ of each of the 60 highest impacts. The bore thickness and velocity was measured at instruments WLDM 2 and PW2 respectively. The bore front slope in Equation 2 was determined based on a sensitivity study of theoretical bore front slopes and optimizing the goodness of fit parameters of the prediction. The optimum bore front slope used in this study was $51^{\circ}$. Additionally, linear regression and fitting of the force peaks to the momentum flux theory by minimizing the MAPE error was done (Equation 14). 


$$
F_{\text {mflux }}=2 \cdot \rho_{w} \cdot \eta_{\max } \cdot v_{\max }^{2} \quad\left[\frac{\mathrm{N}}{\mathrm{m}}\right]
$$

Maximum bore thickness $\eta_{\max }$ and maximum bore velocity $\mathrm{u}_{\max }$ were used for the fitting. Cappietti et al. (2018) suggested that the incoming momentum flux is perfectly reflected $180^{\circ}$ at the wall, and therefore, added the coefficient 2 to the momentum flux theory. The calculated and measured force peaks for the different equations are compared in Figure 6.
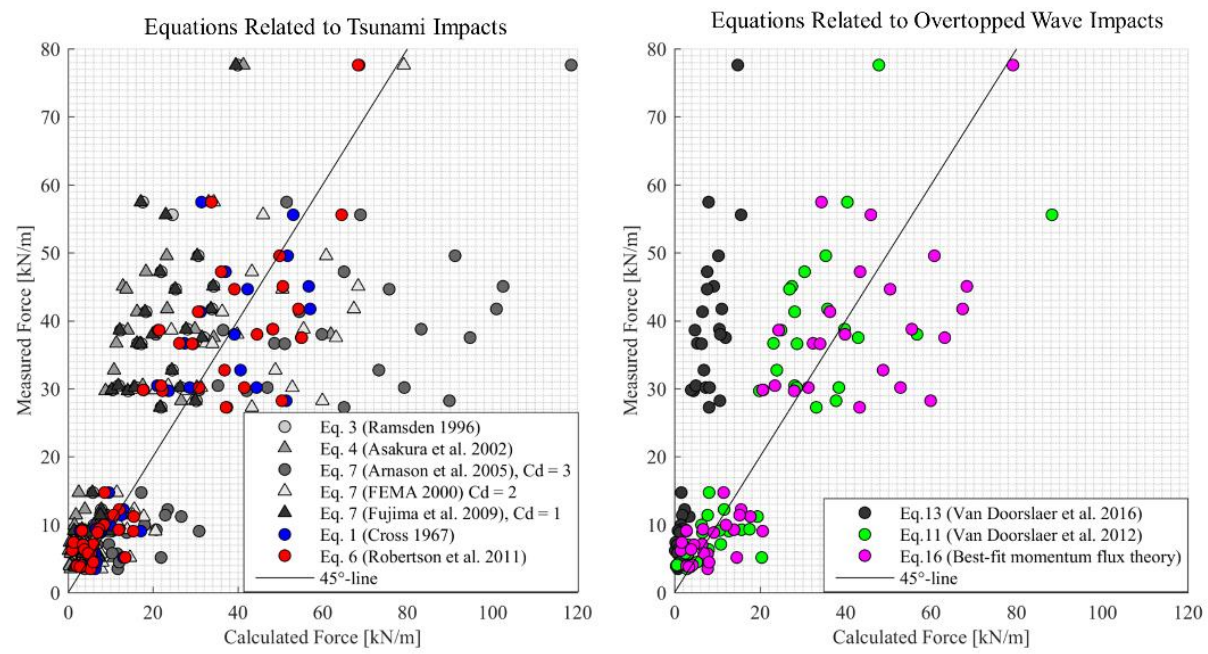

Figure 6: Empirical predicition formulas for the dynamic force peak $F_{1}$, from tsunami related studies (left) and overtopping wave related literature (right). Results are given in prototype-scale units using Froude scaling and the length scaling factor 4.3 .

The standard deviation $\sigma(8.66 \mathrm{kN} / \mathrm{m}-19.32 \mathrm{kN} / \mathrm{m})$ and the mean absolute percentage error MAPE $(0.1980-0.9995)$ for the predictions were calculated and are presented in Table 5 . The values given in brackets have to be treated carefully because these specific prediction results show a bias. Equation 5 (Robertson et al. 2011) yielded in the best goodness of fit parameters, using the maximum bore thickness $\eta_{\max }$ and maximum bore velocity $\mathrm{u}_{\max }$ as input parameters. It was visually observed and confirmed by the goodness of fit parameters that neither the tsunami related nor the overtopping wave related approaches performed exceptionally well in predicting the dynamic force peaks $F_{1}$. Equation 3 (Ramsden 1996), Equation 4 (Asakura et al. 2002) and Equation 10 (Van Doorslaer et al. 2017) under predict the dynamic force peaks $F_{1}$. For the latter this may result from a different wall height in their studies, as this height was included in calculating the freeboard $R_{c}$, or that only non-broken waves and discrete overtopping bores in the lower range were used for the fitting with computed average velocities over the promenade. Conversely, Equation 7 (Arnason et al. 2005) using $C_{D}=3$ over predicts the dynamic force peaks $F_{1}$. Even the drag force theory with $\mathrm{C}_{\mathrm{D}}=2$ (Equation 7) with a different physical meaning (tsunami water passing by buildings as opposed opposite to impact forces on the buildings with dry back sides) show prediction accuracies in the same range of the approaches derived for a situation with short duration overtopping bores (Equation 10) or a wall with a dry back (Equation 5, Equation 4, Equation 1). An overor underestimation of the maximum force peak up to a factor of $\sim 2.2$ was observed.

\begin{tabular}{|c|c|c|c|c|}
\hline Author & Equation & $\sigma$ & $\mathrm{R}^{2}$ & MAPE \\
\hline- & - & $\mathrm{kN} / \mathrm{m}$ & - & - \\
\hline Cross et al. (1967) & Eq. 1 & 9.04 & 0.7615 & 0.9995 \\
\hline Ramsden (1996) & Eq. 3 & 10.35 & $(0.3760)$ & $(0.5875)$ \\
\hline Asakura et al. (2002) & Eq. 4 & 18.58 & $(0.2200)$ & $(0.5418)$ \\
\hline Arnason et al. (2005) & Eq. $7\left(\mathrm{C}_{d}=3\right)$ & 19.32 & $(0.9083)$ & $(0.2560)$ \\
\hline FEMA (2000) & Eq. $7\left(\mathrm{C}_{\mathrm{d}}=2\right)$ & 10.96 & 0.6214 & 0.8373 \\
\hline Fujima et al. (2009) & Eq. $7\left(\mathrm{C}_{\mathrm{d}}=1\right)$ & 10.50 & 0.3563 & 0.5813 \\
\hline Robertson et al. (2011) & Eq. 5 & 8.66 & 0.7800 & 0.96146 \\
\hline Van Doorslaer et al. (2012) & Eq. 9 & 10.80 & 0.6394 & 0.9254 \\
\hline Van Doorslaer et al. (2016) & Eq. 10 & 14.84 & $(0.7163)$ & $(0.1980)$ \\
\hline Best-fit momentum flux theory & Eq. 13 & 10.81 & 0.6214 & 0.8373 \\
\hline
\end{tabular}


The scattered prediction of the dynamic force peaks $F_{1}$ shown in Figure 6 was assumed to be the result from a highly turbulent bore, bore interaction processes prior to impact, and different impact mechanisms. Even small fluctuations in the bore near the wall resulted in a different impact process (e.g. wave interaction in front of the wall might lead to plunging wave breaking against the wall). Two-dimensional effects, such as a non-uniform bore front (Figure 7) and the fact that certain parameters (e.g. the bore front slope) were not studied might also contribute to lower prediction accuracy of the dynamic force peak $F_{1}$. Additionally, the bore thickness $\eta$ and bore velocity $u$ were measured at different locations in experiments from which the different equations were derived, introducing further uncertainty when comparing their predictive capabilities. Nevertheless it seemed more likely that the dynamic force peaks were of stochastic nature, thus hindering a semi-empirical or deterministic prediction having acceptable accuracy. Similar stochastic behavior for overtopped bore impacts was also observed by Chen et al. (2016) and Altomare et al. (2015).

\section{CONCLUSIONS AND OUTLOOK}

Overtopping wave impacts on vertical walls were investigated using large-scale experimental data obtained for a geometrical set-up with mildly sloping foreshore, dike, promenade and wall, in extremely shallow water conditions. The bore impact pressures at the wall were measured together with the bore thickness $\eta$, bore velocity $u$ and run-up at the wall $R_{h}$. A process-based investigation of the impact at the wall was conducted, and dynamic force peaks $F_{1}$ and quasi-static force peaks $F_{2}$ for a double peak impact signal shape were distinguished. In the majority of impacts $(2 / 3)$ the quasi-static force peaks $F_{2}$ were larger than the dynamic force peaks $F_{1}$. The highest force peak $(4.76 \mathrm{kN} / \mathrm{m}$ in model scale) was of quasistatic nature. Ad-hoc comparison of existing formulae to predict the dynamic $F_{1}$ and quasi-static $F_{2}$ force peak was conducted based on data related to 60 maximum impacts. The 60 maximum impacts were derived from two large-scale experiments with $\sim 1000$ irregular waves and wave conditions of storms with 1-in-1000 and 1-in-17000 return periods in extremely shallow foreshore conditions.

A study of the impact process showed that the first dynamic force peak $F_{1}$ was related to the incoming bore thickness and velocity. Simple momentum flux theory was adapted to the data-set and revealed that it was within the range of prediction accuracy of previously proposed formulae. The scatter in all formulae was rather high suggesting a stochastic behavior of the dynamic overtopped bore impacts on walls. Equation 6 (Robertson et al. 2011) resulted in the most accurate prediction $(\sigma=8.6 \mathrm{kN} / \mathrm{m}$ in Prototype, MAPE $=0.9614)$. The process study showed that the second quasi-static force peak $\mathrm{F}_{2}$ was mostly related to the bore thickness in front of the wall or the run-up at the wall. Hence, hydrostatic theory was adapted to the force peaks and a coefficient $\mathrm{C}_{1}=0.32$ derived to predict the maximum quasistatic force peak $F_{2}$ based on the maximum run-up at the wall $R_{h, \max }$. A more practical insight is that only $80 \%$ of the maximum run-up $\mathrm{R}_{\mathrm{h} \text {,max }}$ was effectively causing the force on the wall. This observation was explained by the unweighing of the water body in front of the wall due to upward acceleration, splash up and small or detached run-up tongue of the water in front of the wall. Also for the quasi-static force peaks $\mathrm{F}_{2}$ it was observed that the scatter in the prediction, especially for the larger force peaks, was rather high. The adapted hydrostatic theory (Equation 13), using coefficient $C_{1}=0.32$ resulted in the most accurate prediction $(\sigma=3.23 \mathrm{kN} / \mathrm{m}$ in prototype, MAPE $=0.9963)$.

In conclusion it was observed, that even after examining the physical process, distinguishing impact types related to different physical processes (dynamic $F_{1}$ and quasi-static $F_{2}$ force peaks) and using the most relevant process parameters (either incoming bore thickness and velocity or bore height, run-up height in front of the wall), the prediction accuracy for each of the approaches was low. It was argued that bore interaction processes prior to impact (Streicher et al. 2018, Chen 2016), non-uniformity of the bore front (2D-Effects), air-entrainment in the bore (Chen 2016), even small fluctuations and turbulence in the bore caused different bore impact processes resulting in the stochastic behavior of the force peaks. Statistical analysis was therefore recommended to further predict force peaks for irregular and broken waves in shallow water and mild foreshore conditions. Additionally, the development of bore thickness and bore velocity along the promenade should be studied further to find a most reliable measurement location of this parameters and study their change along the promenade width. Also, parameters such as the bore front slope and its effect on the impact process should be further investigated. To study the effect of the bore front slope and at the same time ensure repeatability, validated numerical modelling might be an option. Especially, the impulsive impacts of very short duration at the first impact of the bore tip with the wall were expected to be largely dependent on the bore front slope and need to be further investigated. 
Furthermore, a study of scale effects due to dissimilarities in the entrained air and resulting cushioning effects of the impacts, with respect to the different impact types $\left(\mathrm{F}_{1}\right.$ and $\left.\mathrm{F}_{2}\right)$, is highly recommended.

\section{ACKNOWLEDGMENTS}

The work described in this publication was supported by the European Community's Horizon 2020

Research and Innovation Programme through the grant to HYDRALAB-PLUS, Contract no. 654110.

\section{REFERENCES}

Arnason, H., C. Petroff, H. Yeh. 2009. Tsunami bore impingement onto a vertical column, Journal of Disaster Research 4, 391-403. doi: 10.20965/jdr.2009.p039.

Arnason, H. 2005. Interactions between an Incident Bore and a Free-Standing Coastal Structure, Ph.D. Thesis, University of Washington, Seattle, $172 \mathrm{pp}$.

Asakura, R., K. Iwase, T. Ikeya, M. Takao, T. Kaneto, N. Fujii, M., and Ohmori. 2002. The tsunami wave force acting on land structures, Proceedings of the $28^{\text {th }}$ International Conference on Coastal Engineering, ASCE, 1191-1202.

Allsop N.W.H. 2005. CLASH Work Package 6: Analysis of overtopping hazards, Report D38, publn. HR Wallingford and University of Ghent, see: http://www.clash-eu.org/.

Bukreev, V.I. 2009. Dynamic action of a tsunami wave traveling along a channel, Journal of Fluid Dynamics 44 (3), 442-447, https://doi.org/10.1134/S0015462809030120.

Cappietti, L., Simonetti, I., Esposito, A., Streicher, M., Kortenhaus, A., Scheres, B., Schuettrumpf, H., Hirt, M., Hofland, B., Chen, X. 2018. Large-scale experiments of wave-overtopping loads on walls: Layer thicknesses and velocities, $37^{\text {th }}$ International conference on ocean, offshore and arctic engineering, Madrid, Spain, 6 pp.

Chen, X. 2016. Impacts of overtopping waves on buildings on coastal dikes, PhD diss., TU Delft, doi: 10.4233/uuid:e899b6e4-fcbe-4e05-b01f-116901eabfef.

Chen, X., B. Hofland, C. Altomare, T. Suzuki, W. Uijttewaal. 2016. Forces on a vertical wall on a dike crest due to overtopping flow, Coastal Engineering 96, 94-104, doi: 10.1016/j.coastaleng.2014.10.002.

Chen, X., B. Hofland, C. Altomare, T. Suzuki, W. Uijttewaal. 2015. Forces on a vertical wall on a dike crest due to overtopping flow, Coastal Engineering 95, 94-104, doi: 10.1016/j.coastaleng.2014.10.002.

Chen, X., B. Hofland, C. Altomare, W. Uijttewaal. 2014. Overtopping flow impact on a vertical wall on a dike crest, Proceedings of $34^{\text {th }}$ conference on coastal engineering, Seoul, South Korea, 1-10. https://doi.org/10.9753/icce.v34.structures.4.

Chen, X. , W. Hassan, W. Uijttewaal, T. Verwaest, H. J. Verhagen, T. Suzuki, S. N. Jonkman. 2012. Hydrodynamic load on the building caused by overtopping waves, Proceedings of $33^{\text {rd }}$ conference on coastal engineering, Santander, Spain, 1-11 pp. https://doi.org/10.9753/icce.v33.structures.59.

Cross, R. H. 1967. Tsunami surge forces, Journal of the Waterways and Harbors Division 93 (4), 201-231.

Cumberbatch, E., 1960. The impact of a water wedge on a wall, Journal of Fluid Mechanics 7, 353-374. doi:10.1017/S002211206000013X.

Den Heijer, F. 1998. Gofloverslag en krachten op verticale waterkeringsconstructies, Report, Rijkswaterstaat, Dienst Weg- en Waterbouwkunde.

De Rouck, J., K. Van Doorslaer, T. Versluys,. K. Ramachandran, S. Schimmels, M. Kudella, K. Trouw. 2012. Full scale impact tests of an overtopping bore on a vertical wall in the large wave flume (GWK) in Hannover, Proceedings of $33^{\text {rd }}$ conference on coastal engineering, Santander, Spain, 1-11, https://doi.org/10.9753/icce.v33.structures.62.

EurOtop, 2016. Manual on wave overtopping of sea defences and related structures. Van der Meer, J.W., Allsop, W., Bruce, T., De Rouck, J., Kortenhaus, A., Pullen, T., Schüttrumpf, H., Troch, P., Zanuttigh, B.

FEMA 55. 2000. Coastal Construction Manual, Federal Emergency Management Agency, Washington DC, USA.

Fujima, K., Achmad, F., Shigihara, Y., and Mizutani, N. 2009. Estimation of tsunami force acting on rectangular structures, Journal of Disaster Research 4, 404-409.

Hofland, B., Chen, X., Altomare, C., Oosterlo, P. 2017. Prediction formula for the spectral period $\mathrm{T}_{\mathrm{m}-1,0}$ on mildly sloping shallow foreshores, Coastal Engineering 123, 21-28.

IPCC, 2014: Climate Change 2014: Synthesis Report. Contribution of Working Groups I, II and III to the Fifth Assessment Report of the Intergovernmental Panel on Climate Change [Core Writing Team, R.K. Pachauri and L.A. Meyer (eds.)]. IPCC, Geneva, Switzerland, 151 pp.

Kihara, N., Niida, Y., Takabatake, D., Kaida, H., Shibayama, A., Miyagawa, Y. 2015. Large-scale experiments on tsunami-induced pressure on a vertical tide wall, Coastal Engineering 99, 46-63, doi: 10.1016/j.coastaleng.2015.02.009.

Klammer, P, Kortenhaus, A., Oumeraci, H. 1996. Wave impact loading of vertical face structures for dynamic stability analysis- prediction formulae, $25^{\text {th }}$ International conference on coastal engineering, Orlando, Florida, USA.

Kleidon, P. 2014. Modelluntersuchungen zum Wellenüberlauf eines geschütteten Wellenbrechers und zur überlaufinduzierten Gefährdung von Personen auf Kronenbauwerken, Master's theses, Leichtweiß-Institut für Wasserbau, TU Braunschweig, Germany. 
Kortenhaus, A., D. Gallach Sanchez, M. Streicher, C. Hohls, K. Trouw, C. Altomare, T. Suzuki, D. Thoon, P. Troch, J. De Rouck. 2017. Wave Overtopping and Wave-induced Loads on Coastal Sea Walls, Coastal structures and solutions to coastal disaster joint conference, Boston, USA, 1-7, https://doi.org/10.1061/9780784480304.068.

Lubin, P., Chanson H., 2017. Are breaking waves, bores, surges and jumps the same flow?. Environmental Fluid Mechanics, 17 (1), 47-77. doi: 10.1007/s10652-016-9475-y.

Mansard, E.P.D. and Funke, E.R., 1980. The measurement of incident and reflected spectra using a least squares method, International conference on coastal engineering, Hamburg, Germany, 154-169.

Martin, F.L., M.A. Losada, and R. Medina. 1999. Wave loads on rubble mound breakwater crown wall, Coastal Engineering 37, 149-174.

Oumeraci, H., P. Klammer, H. Partenscky. 1993. Classification of breaking wave loads on vertical structures, Journal of Waterway, Port, Coastal, and Ocean Engineering 119, 381-397. https://doi.org/10.1061/(ASCE)0733-950X(1993)119:4(381).

Ramachandran, K., R. Genzalez, H. Oumeraci, S. Schimmels, M. Kudella, K. Van Doorslaer, J. De Rouck, T. Versluys, K. Trouw. 2012. "Loading of vertical walls by overtopping bores using pressure and force sensors - a large scale model study." Proceedings of $33^{\text {rd }}$ conference on coastal engineering, Santander, Spain, 1-15, https://doi.org/10.9753/icce.v33.currents.44.

Ramsden, J.D. 1996. Forces on a vertical wall due to long waves, bores and dry-bed surges, Journal of Waterway, Port, Coastal, and Ocean Engineering 122, 134-141, https://doi.org/10.1061/(ASCE)0733950X(1996)122:3(134).

Ramsden, J.D. 1993. Tsunamis: Forces on a vertical wall caused by long waves, bores, and surges on a dry bed, Report No. KH-R-54, W.M. Keck Laboratory, California Institute of Technology, Pasadena, Calif., 251 pp.

Streicher, M., Kortenhaus, A., Marinov, K., Hirt, M., Hughes, S., Hofland, B., Scheres, B., Schüttrumpf, H. 2018. Process based classification of short-duration overtopped bores impacting a dike mounted vertical wall, Coastal Engineering Journal, (under review).

Streicher, M., A. Kortenhaus, C. Altomare, V. Gruwez, B. Hofland, X. Chen, K. Marinov, B. Scheres, H. Schüttrumpf, M. Hirt, L. Cappietti, A. Esposito, A. Saponieri, N. Valentini, G. Tripepi, D. Pasquali, M. D. Risio, F. Aristodemo, L. Damiani, M. Willems., D. Vanneste, T.Suzuki, M. Klein Breteler, D. Kaste. 2017. WALOWA (Wave Loads on Walls) - Large-scale experiments in the Delta Flume, Proceedings of the $8^{\text {th }}$ SCACR conference, Santander, Spain, 2017, 1-11, doi: 10.5281/zenodo.834874.

Tanimoto, K., Tsuruya, H. and Nakano, S. 1984. Experimental Study of Tsunami Force and Investigation of the Cause of Sea Wall Damage During 1983 Nihonkai Chubu Earthquake, Proc. $31^{\text {st }}$ Japanese Conference Coastal Engineering, 257-261 (in Japanese).

Van Der Meer, J. W., Hardeman, B., Steendam, G.-J., Schüttrumpf, H., Verheij, H. 2010. Flow depths and velocities at crest and landward slope of a dike, in theory and with the wave overtopping simulator. Proceedings of $32^{\text {nd }}$ conference on coastal engineering, Shanghai, China, 1-15, doi:https://doi.org/10.9753/icce.v32.structures.10.

Doorslaer, K., A. Romano, J. De Rouck, A. Kortenhaus. 2017. Impacts on a storm wall caused by non-breaking waves overtopping a smooth dike slope, Coastal Engineering 120, 93-111, doi: 10.1016/j.coastaleng.2016.11.010.

Van Doorslaer, K., A. Romano, J. De Rouck, A. Kortenhaus. 2017. Impacts on a storm wall caused by non-breaking waves overtopping a smooth dike slope, Coastal Engineering 120, 93-111, doi: 10.1016/j.coastaleng.2016.11.010.

Van Doorslaer, K., J. De Rouck, J.W. Van der Meer, K. Trouw. 2012. Full scale wave impact tests on a vertical wall using the wave overtopping simulator, Proceedings of $33^{\text {rd }}$ conference on coastal engineering, Santander, Spain, 2012, 1-6.

Verwaest, T., Hassan, W., Reyns, J., Balens, N., Trouw, K., De Rouck, J., Van Doorslaer, K., Troch, P. 2011. Hydrodynamic loading of wave return walls on top of seaside promenades, $6^{\text {th }}$ International conference on coastal structures, Yokohama, Japan, 568-576.

Wüthrich, D., 2017. Impact of a dry bed surge against structures with and without openings, Proceedings of $37^{\text {th }}$ IAHR World congress, Kuala Lumpur, Malaysia, $10 \mathrm{pp}$.

Yeh, H. 2006. Maximum fluid forces in the tsunami runup zone, Journal of Waterway, Port, Coastal and Ocean Engineering 132 (6), 496 -500, https://doi.org/10.1061/(ASCE)0733-950X(2006)132:6(496)

\section{DISCLAIMER}

This document reflects only the authors' views and not those of the European Community. This work may rely on data from sources external to the HYDRALAB-PLUS project Consortium. Members of the Consortium do not accept liability for loss or damage suffered by any third party as a result of errors or inaccuracies in such data. The information in this document is provided "as is" and no guarantee or warranty is given that the information is fit for any particular purpose. The user thereof uses the information at its sole risk and neither the European Community nor any member of the HYDRALABPLUS Consortium is liable for any use that may be made of the information 